\title{
Role of Esophageal Mean Nocturnal Baseline Impedance and Post-reflux Swallow-induced Peristaltic Wave Index in Discriminating Chinese Patients With Heartburn
}

\author{
Ya Mei Sun, ${ }^{1}$ Yan Gao, ${ }^{2}$ and Feng Gao ${ }^{1 *}$ \\ ${ }^{I}$ Department of Gastroenterology, Beijing Anzhen Hospital, Capital Medical University, Beijing; China; and ${ }^{2}$ Department of Gastroenterology, \\ Beijing Chaoyang Hospital, Capital Medical University, Beijing; China
}

\section{Background/Aims}

Recently, esophageal mean nocturnal baseline impedance (MNBI) and post-reflux swallow-induced peristaltic wave (PSPW) index have been proposed, which can increase the diagnostic role of multichannel intraluminal impedance and pH recording (MII/pH) for differentiating patients with heartburn. Therefore, our aim is to investigate the role of esophageal proximal MNBI, distal MNBI, and PSPW index in differentiating Chinese patients with heartburn.

\section{Methods}

Patients with heartburn from the Beijing Anzhen Hospital, who underwent upper gastrointestinal endoscopy and 24-hour Mll/pH, were enrolled in this study.

\section{Results}

In all, 24 erosive esophagitis (EE), 46 non-erosive reflux disease (NERD), 52 reflux hypersensitivity (RH), and 78 functional heartburn (FH) patients were recruited. The respective median values for the EE, NERD, RH, and FH groups were as follows: proximal MNBI 1858.0, 2147.5, 2374.3, and 2329.0 $\Omega(P=0.053)$; distal MNBI 1243.4, 1506.5, 2451.2, and $2477.3 \Omega(P<0.001)$; and PSPWI $15.0 \%, 25.0 \%, 25.0 \%$, and $45.0 \%(P<0.001)$. Spearman correlation analysis showed that distal MNBI and PSPW index were significantly negatively correlated with acid and bolus exposure time and acid reflux events. Receiver operating characteristic analyses showed that distal MNBI and PSPW index significantly discriminated FH from EE, NERD, and RH $(P<0.001)$, with cut-off values of $1890.6 \Omega$ and $27.5 \%$ and areas under the curve of 0.721 and 0.779 , respectively.

\section{Conclusion}

Esophageal distal MNBI and PSPW index could increase the diagnostic role of MII/pH, especially for differentiating Chinese patients with heartburn.

(J Neurogastroenterol Motil 2019;25:515-520)

\section{Key Words}

Electric impedance; Esophagitis, peptic; Gastroesophageal reflux; Heartburn

Received: March 13, 2019 Revised: None Accepted: July 20, 2019

(.) This is an Open Access article distributed under the terms of the Creative Commons Attribution Non-Commercial License (http://creativecommons. org/licenses/by-nc/4.0) which permits unrestricted non-commercial use, distribution, and reproduction in any medium, provided the original work is properly cited.

*Correspondence: Feng Gao, MD

Department of Gastroenterology, Beijing Anzhen Hospital, Capital Medical University, Beijing 100029, China Tel: +86-10-64456475, Fax: +86-10-64456975, E-mail: gaofeng4321@sina.com 


\section{Introduction}

Heartburn is a typical symptom of gastroesophageal reflux disease (GERD). Subjects with GERD can be classified as having either erosive esophagitis (EE) or non-erosive reflux disease (NERD) based on endoscopic examination. With 24-hour multichannel intraluminal impedance and $\mathrm{pH}$ recording $(\mathrm{MII} / \mathrm{pH}), \mathrm{NERD}$ can be further categorized into 3 phenotypes: true NERD, reflux hypersensitivity $(\mathrm{RH})$, and functional heartburn $(\mathrm{FH}) .{ }^{1}$ Subjects with abnormal acid exposure time (AET) are diagnosed with true NERD. Subjects without objective evidence of reflux (normal upper gastrointestinal endoscopy and normal AET), but have a positive correlation between symptoms and reflux events are diagnosed with reflux hypersensitivity ( $\mathrm{RH})$. In contrast, subjects with normal upper gastrointestinal endoscopy, normal AET and reflux episodes, and no correlation between symptoms and reflux events are diagnosed with functional heartburn $(\mathrm{FH}){ }^{1-4}$

Recently, esophageal proximal mean nocturnal baseline impedance (MNBI), distal MNBI, and post-reflux swallow-induced peristaltic wave (PSPW) index have been proposed, which can increase the diagnostic role of $\mathrm{MII} / \mathrm{pH}$ for differentiating patients with heartburn. ${ }^{5-8}$ However, no study has explored the difference between proximal MNBI, distal MNBI, and PSPW index in Chinese patients with heartburn. Therefore, we investigated the role of esophageal proximal MNBI, distal MNBI, and PSPW index in differentiating Chinese patients with heartburn.

\section{Materials and Methods}

\section{Ethics}

The study was approved by the Beijing Anzhen Hospital Medical Ethics Committee (Serial No. 2017058X).

\section{Patient Selection}

Patients with heartburn from the Beijing Anzhen, who underwent upper gastrointestinal endoscopy and $\mathrm{MII} / \mathrm{pH}$ between January, 2014 and December, 2017, were selected. Patients with heartburn were diagnosed with EE by endoscopy. Endoscopy was performed whether or not the proton pump inhibitor (PPI) was prescribed and PPI was effective treatment in $41 \%$ of patients. Patients with an operation history of the stomach or esophagus, patients with eosinophilic esophagitis, or patients with esophageal motility disorders were excluded. Those with a normal upper gas- trointestinal endoscopy and abnormal AET $(>6 \%)$ and/or reflux episodes $(>80)$ were diagnosed with NERD. ${ }^{9,10}$ Those without objective evidence of reflux (normal endoscopy and AET), but show a positive correlation between symptoms were diagnosed with $\mathrm{RH},{ }^{1}$ and those without objective evidence of reflux and symptom correlation were diagnosed with $\mathrm{FH}^{1-3}$

\section{Multichannel Intraluminal Impedance and pH Recording}

Outpatients undertook $\mathrm{MII} / \mathrm{pH}$ after fasting for night. The position of the lower esophageal sphincter was estimated using esophageal manometry. $\mathrm{MII} / \mathrm{pH}$ was performed after a week of washout of PPI or histamine $\mathrm{H} 2$ receptor antagonists.

Upright, recumbent, and total AET, and acid, nonacid, and total reflux events, were recorded. ${ }^{11}$ The DeMeester score was calculated. The symptom index $\geq 50 \%$ and/or symptom association probability $\geq 95 \%$ was considered positive for symptom correlation. ${ }^{12,13}$ MNBI was measured from the impedance channels of $\mathrm{MII} / \mathrm{pH} .{ }^{14}$ Proximal MNBI was measured as the mean value of proximal 2 channels and distal MNBI was measured as the mean value of distal 4 channels. ${ }^{15}$ A PSPW was defined as a $50 \%$ drop in impedance from proximal to all distal impedance sites. PSPW also met the condition that wave reached the lowest distal impedance site and this should be occurred within 30 seconds after the reflux. PSPW index was calculated manually as the number of PSPW divided by the number of total refluxes. ${ }^{16}$ All data were recorded and analyzed by Dr Y.M.S., using Bio-View Analysis software (Sandhill Scientific Inc, Highlands Ranch, CO, USA).

\section{Comparison Groups}

Four study groups were compared: Chinese EE, NERD, RH, and $\mathrm{FH}$ subjects.

\section{Statistical Methods}

Categorical data were described as numbers, and continuous data with a non-normal distribution were presented as median (interquartile range $[\mathrm{IQR}])$. Data were compared using KruskalWallis or $\chi^{2}$ tests. Between-group comparison was performed using Mann-Whitney $U$ test with Bonferroni correction. Spearman's correlation analysis was performed to assess the correlations among parameters. Receiver operating characteristic (ROC) curves were obtained followed by calculation of the area under the curve (AUC) and cut-off values to assess the ability of a parameter to distinguish FH from EE, NERD, and RH. $P<0.05$ was taken to indicate statistical significance for each test. All data were analysed with the 
Table 1. Demographic Data and 24-hour Multichannel Intraluminal Impedance and pH Recording Results

\begin{tabular}{|c|c|c|c|c|c|}
\hline \multirow{2}{*}{ Items } & Erosive esophagitis & NERD & Reflux hypersensitivity & Functional heartburn & \multirow{2}{*}{$P$-value } \\
\hline & $(\mathrm{n}=24)$ & $(\mathrm{n}=46)$ & $(\mathrm{n}=52)$ & $(\mathrm{n}=78)$ & \\
\hline Age (yr) & $\begin{array}{c}56.0 \\
(49.0-63.0)\end{array}$ & $\begin{array}{c}59.0 \\
(52.0-63.0)\end{array}$ & $\begin{array}{c}53.5 \\
(44.5-61.5)\end{array}$ & $\begin{array}{c}55.0 \\
(44.0-63.0)\end{array}$ & 0.123 \\
\hline \multicolumn{5}{|l|}{$\operatorname{MNBI}(\Omega)$} & 0.199 \\
\hline Proximal MNBI & $\begin{array}{c}1858.0 \\
(1580.0-2476.0)\end{array}$ & $\begin{array}{c}2147.5 \\
(1654.4-2699.8)\end{array}$ & $\begin{array}{c}2374.3^{\mathrm{a}} \\
(1872.1-2832.8)\end{array}$ & $\begin{array}{c}2329.0^{\mathrm{a}} \\
(2013.8-2936.8)\end{array}$ & 0.053 \\
\hline Distal MNBI & $\begin{array}{c}1243.4 \\
(908.5-1686.6)\end{array}$ & $\begin{array}{c}1506.5^{\mathrm{a}} \\
(1104.4-2085.6)\end{array}$ & $\begin{array}{c}2451.2^{\mathrm{a}, \mathrm{b}} \\
(1911.6-2764.5)\end{array}$ & $\begin{array}{c}2477.3^{\mathrm{a}, \mathrm{b}} \\
(2010.6-2986.2)\end{array}$ & $<0.001$ \\
\hline PSPW index (\%) & $\begin{array}{c}15.0 \\
(15.0-35.0)\end{array}$ & $\begin{array}{c}25.0 \\
(15.0-27.5)\end{array}$ & $\begin{array}{c}25.0^{\mathrm{a}, \mathrm{b}} \\
(25.0-47.5)\end{array}$ & $\begin{array}{c}45.0^{\mathrm{a}, \mathrm{b}, \mathrm{c}} \\
(30.0-60.0)\end{array}$ & $<0.001$ \\
\hline DeMeester score & $\begin{array}{c}24.9 \\
(18.9-34.7)\end{array}$ & $\begin{array}{c}22.2 \\
(17.9-29.9)\end{array}$ & $\begin{array}{c}3.6^{\mathrm{a}, \mathrm{b}} \\
(1.6-6.7)\end{array}$ & $\begin{array}{c}2.0^{\mathrm{a}, \mathrm{b}} \\
(0.9-4.5)\end{array}$ & $<0.001$ \\
\hline \multicolumn{6}{|l|}{ Acid exposure (\%) } \\
\hline Upright & $\begin{array}{c}7.1 \\
(3.8-15.8)\end{array}$ & $\begin{array}{c}8.6 \\
(5.2-10.1)\end{array}$ & $\begin{array}{c}1.2^{\mathrm{a}, \mathrm{b}} \\
(0.3-2.9)\end{array}$ & $\begin{array}{c}0.7^{\mathrm{a}, \mathrm{b}} \\
(0.1-1.8)\end{array}$ & $<0.001$ \\
\hline Recumbent & $\begin{array}{c}5.5 \\
(0.7-10.0)\end{array}$ & $\begin{array}{c}3.9 \\
(0.7-9.2)\end{array}$ & $\begin{array}{c}0.0^{\mathrm{a}, \mathrm{b}} \\
(0.0-0.4)\end{array}$ & $\begin{array}{c}0.0^{\mathrm{a}, \mathrm{b}} \\
(0.0-0.4)\end{array}$ & $<0.001$ \\
\hline Total & $\begin{array}{c}7.0 \\
(5.0-10.5)\end{array}$ & $\begin{array}{c}5.9 \\
(4.7-8.7)\end{array}$ & $\begin{array}{c}0.9^{\mathrm{a}, \mathrm{b}} \\
(0.3-1.5)\end{array}$ & $\begin{array}{c}0.5^{\mathrm{a}, \mathrm{b}} \\
(0.1-1.0)\end{array}$ & $<0.001$ \\
\hline \multicolumn{6}{|l|}{ Bolus exposure (\%) } \\
\hline Upright & $\begin{array}{c}4.1 \\
(1.9-5.7)\end{array}$ & $\begin{array}{c}3.1 \\
(2.0-6.6)\end{array}$ & $\begin{array}{c}2.1^{\mathrm{a}, \mathrm{b}} \\
(1.1-3.1)\end{array}$ & $\begin{array}{c}1.5^{\mathrm{a}, \mathrm{b}, \mathrm{c}} \\
(0.9-2.4)\end{array}$ & $<0.001$ \\
\hline Recumbent & $\begin{array}{c}0.9 \\
(0.1-2.1)\end{array}$ & $\begin{array}{c}0.6 \\
(0.1-1.5)\end{array}$ & $\begin{array}{c}0.0^{\mathrm{a}, \mathrm{b}} \\
(0.0-0.6)\end{array}$ & $\begin{array}{c}0.2^{\mathrm{a}, \mathrm{b}} \\
(0.0-0.5)\end{array}$ & $<0.001$ \\
\hline Total & $\begin{array}{c}2.6 \\
(1.5-3.8)\end{array}$ & $\begin{array}{c}2.1 \\
(1.1-4.1)\end{array}$ & $\begin{array}{c}1.3^{\mathrm{a}, \mathrm{b}} \\
(0.7-2.0)\end{array}$ & $\begin{array}{c}0.8^{\mathrm{a}, \mathrm{b}, \mathrm{c}} \\
(0.5-1.4)\end{array}$ & $<0.001$ \\
\hline \multicolumn{6}{|l|}{ Reflux event (n) } \\
\hline Proximal acid & $\begin{array}{c}13.0 \\
(4.0-23.0)\end{array}$ & $\begin{array}{c}12.0 \\
(7.75-21.50)\end{array}$ & $\begin{array}{c}8.0^{\mathrm{a}, \mathrm{b}} \\
(3.0-11.5)\end{array}$ & $\begin{array}{c}5.5^{\mathrm{a}, \mathrm{b}} \\
(2.0-10.0)\end{array}$ & $<0.001$ \\
\hline Proximal nonacid & $\begin{array}{c}10.5 \\
(6.0-16.0)\end{array}$ & $\begin{array}{c}8.0 \\
(4.0-15.0)\end{array}$ & $\begin{array}{c}8.5 \\
(5.0-15.0)\end{array}$ & $\begin{array}{c}6.0^{\mathrm{a}} \\
(3.0-10.0)\end{array}$ & 0.068 \\
\hline Proximal total & $\begin{array}{c}25.0 \\
(18.5-37.5)\end{array}$ & $\begin{array}{c}22.0 \\
(16.5-33.5)\end{array}$ & $\begin{array}{c}14.5^{\mathrm{a}, \mathrm{b}} \\
(8.0-25.0)\end{array}$ & $\begin{array}{c}11.0^{\mathrm{a}, \mathrm{b}} \\
(7.0-20.0)\end{array}$ & $<0.001$ \\
\hline Distal acid & $\begin{array}{c}27.5 \\
(18.0-42.5)\end{array}$ & $\begin{array}{c}27.0 \\
(17.0-36.0)\end{array}$ & $\begin{array}{c}11.0^{\mathrm{a}, \mathrm{b}} \\
(6.0-17.0)\end{array}$ & $\begin{array}{c}9.0^{\mathrm{a}, \mathrm{b}} \\
(4.0-15.0)\end{array}$ & $<0.001$ \\
\hline Distal nonacid & $\begin{array}{c}15.0 \\
(9.0-26.0)\end{array}$ & $\begin{array}{c}15.0 \\
(8.0-23.0)\end{array}$ & $\begin{array}{c}22.0^{\mathrm{b}} \\
(12.0-27.0)\end{array}$ & $\begin{array}{c}13.5^{\mathrm{c}} \\
(9.0-21.5)\end{array}$ & 0.035 \\
\hline Distal total & $\begin{array}{c}47.0 \\
(34.5-66.5)\end{array}$ & $\begin{array}{c}44.0 \\
(29.0-55.0)\end{array}$ & $\begin{array}{c}31.0^{\mathrm{a}} \\
(23.0-42.5)\end{array}$ & $\begin{array}{c}26.5^{\mathrm{a}, \mathrm{b}, \mathrm{c}} \\
(15.5-35.5)\end{array}$ & $<0.001$ \\
\hline
\end{tabular}

${ }^{a} P$-value $<0.001$ compared with erosive esophagitis.

${ }^{\mathrm{b}} P$-value $<0.001$ compared with non-erosive reflux disease (NERD).

${ }^{\mathrm{c}} P$-value $<0.001$ compared with reflux hypersensitivity.

Mann-Whitney $U$ test was used to compare the differences between the 2 groups.

M, male; F, female; MNBI, mean nocturnal baseline impedance; PSPW, post-reflux swallow-induced peristaltic wave.

Data are presented as median (interquartile range $[\mathrm{IQR}]$ ). 

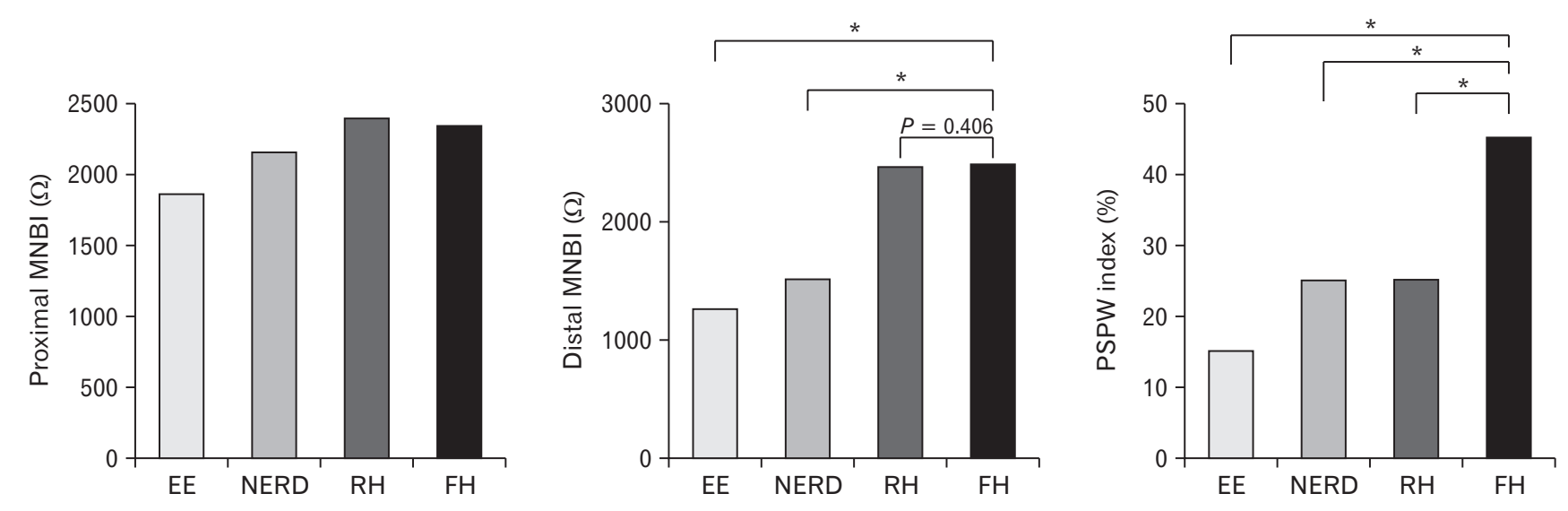

Figure 1. The result of proximal mean nocturnal baseline impedance (MNBI), distal MNBI, and post-reflux swallow-induced peristaltic wave (PSPW) index for erosive esophagitis (EE), non-erosive reflux disease (NERD), reflux hypersensitivity (RH), and functional heartburn (FH) groups. * $P<0.001$.

Table 2. Correlation Coefficients From Spearman Correlation Analysis

\begin{tabular}{lccc}
\multicolumn{1}{c}{ Items } & $\begin{array}{c}\text { Proximal } \\
\text { MNBI }\end{array}$ & $\begin{array}{c}\text { Distal } \\
\text { MNBI }\end{array}$ & $\begin{array}{c}\text { PSPW } \\
\text { index }\end{array}$ \\
\hline $\begin{array}{l}\text { DeMeester score } \\
\text { Acid exposure }\end{array}$ & -0.177 & -0.589 & -0.496 \\
Upright & NS & -0.446 & -0.405 \\
Recumbent & NS & -0.492 & -0.414 \\
Total & -0.177 & -0.587 & -0.494 \\
Bolus exposure & & & \\
Upright & NS & -0.352 & -0.392 \\
Recumbent & NS & -0.371 & -0.286 \\
Total & NS & -0.399 & -0.397 \\
Reflux event & & & \\
Proximal acid & NS & -0.244 & -0.229 \\
Proximal total & NS & -0.242 & -0.230 \\
Distal acid & NS & -0.362 & -0.318 \\
Distal total & NS & -0.228 & -0.276 \\
\hline
\end{tabular}

MNBI, mean nocturnal baseline impedance; PSPW, post-reflux swallowinduced peristaltic wave; NS, not significant.

SPSS software (version 21.0; IBM Corp, Armonk, NY, USA).

\section{Results}

The study enrolled 200 outpatients with heartburn who underwent upper gastrointestinal endoscopy and $\mathrm{MII} / \mathrm{pH}$. Of these, 24, 46, 52, and 78 were diagnosed with EE, NERD, RH, and $\mathrm{FH}$, respectively. There was no significant difference in age and sex among the 4 groups.

Table 1 shows the MII/pH results of the 4 groups. The respective median (IQR) values for the EE, NERD, RH, and $\mathrm{FH}$
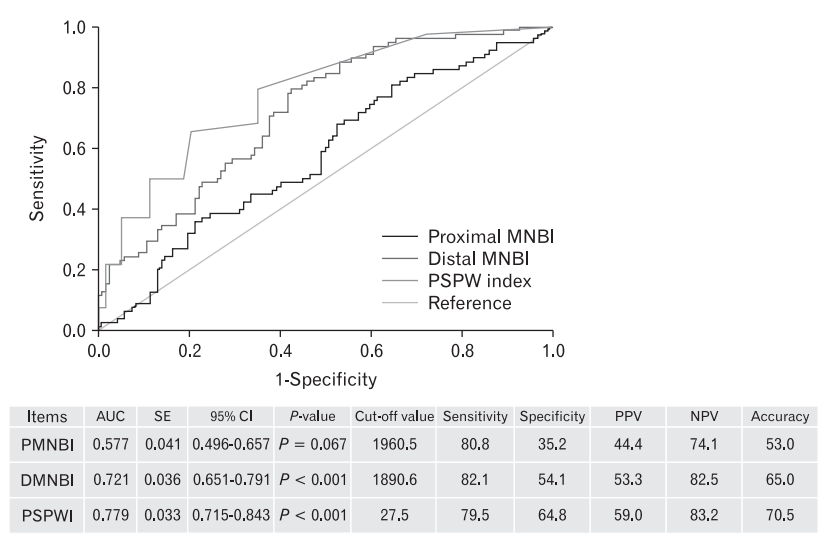

Figure 2. Receiver operating characteristic (ROC) curves for distinguishing functional heartburn $(\mathrm{FH})$ from erosive esophagitis (EE), non-erosive reflux disease (NERD), and reflux hypersensitivity (RH). In ROC analyses, proximal mean nocturnal baseline impedance (MNBI), distal MNBI, and post-reflux swallow-induced peristaltic wave (PSPW) index yielded areas under the curve (AUC) of 0.577 , 0.721 , and 0.779 , with cut-off values of $1960.5 \Omega, 1890.6 \Omega$, and $27.5 \%$, respectively. Distal MNBI and PSPW index could significantly distinguish FH from EE, NERD, and RH. SE, standard error; CI, confidence interval; PPV, positive predictive value; NPV, negative predictive value.

groups were as follows: proximal MNBI (1858.0 [1580.0-2476.0], 2147.5 [1654.4-2699.8], 2374.3 [1872.1-2832.8], and 2329.0 [2013.8-2936.8] $\Omega ; P=0.053)$; distal MNBI (1243.4 [908.51686.6], 1506.5 [1104.4-2085.6], 2451.2 [1911.6-2764.5], and 2477.3 [2010.6-2986.2] $\Omega ; P<0.001)$; and PSPW index (15.0\% [15.0-35.0], 25.0\% [15.0-27.5], 25.0\% [25.0-47.5], and 45.0\% [30.0-60.0]; $P<0.001)$, respectively. The results of proximal 
MNBI, distal MNBI, and PSPW index for the EE, NERD, $\mathrm{RH}$, and $\mathrm{FH}$ groups are also exhibited in Figure 1. The 4 groups also exhibited significant differences in AET, bolus exposure time, and acid and total reflux events $(P<0.001)$. However, the 4 groups showed similar proximal nonacid reflux events $(P=0.068)$.

Table 2 shows the results of Spearman's correlation analysis. Distal MNBI and PSPW index significantly negatively correlated with DeMeester score, AET, bolus exposure time, and acid and total reflux events. However, distal MNBI and PSPW index were not correlated with nonacid reflux events. Proximal MNBI was only significantly negatively correlated with DeMeester score and total AET.

In ROC analyses, proximal MNBI, distal MNBI, and PSPW index yielded areas under the curve of $0.577,0.721$, and 0.779 , with cut-off values of $1,960.5 \Omega, 1890.6 \Omega$, and $27.5 \%$, respectively. Distal MNBI and PSPW index could significantly distinguish FH from EE, NERD, and RH (Fig. 2).

\section{Discussion}

According to the Lyon consensus, the modern diagnosis of gastroesophageal reflux disease (GERD) discriminates evidence of reflux into conclusive evidence for pathological reflux, borderline or inconclusive evidence, adjunctive or supportive evidence, and evidence against pathological reflux, depending on the results of upper gastrointestinal endoscopy, $\mathrm{MII} / \mathrm{pH}$, and high-resolution manometry (HRM). ${ }^{10}$ Any conclusive finding (Los Angeles C or D esophagitis, long-segment Barrett's esophagus or peptic esophageal stricture, or AET > 6\%) can clearly diagnose GERD. A normal upper gastrointestinal endoscopy combining with AET $<4 \%$ and reflux episodes $<40$ can rule out the diagnosis of GERD. When inconclusive findings (Los Angeles A or B esophagitis, AET 4-6\%, and reflux episodes 40-80) arise, further supportive findings (esophageal histopathology, electron microscopy, low mucosal impedance, positive symptom association probability, reflux episodes $>$ 80, low MNBI, low PSPW index, hypotensive esophagogastric junction, hiatus hernia, or ineffective esophageal motility) can increase confidence regarding the presence or absence of GERD. Therefore, $\mathrm{MII} / \mathrm{pH}$ and $\mathrm{HRM}$ can provide conclusive or supportive evidence of GERD.

$\mathrm{RH}$ is used to identify patients without evidence of pathological reflux, but with demonstrable triggering of symptoms (heartburn) with physiological reflux. ${ }^{1}$ Hence, combining upper gastrointestinal endoscopy with $\mathrm{MII} / \mathrm{pH}$ allows patients with heartburn to be discriminated into EE, NERD, RH, and FH groups. Apart from acid suppression, various treatments such as diet and lifestyle modification, anti-reflux surgery, modulation of pain perception, and alternative therapies may be appropriate for $\mathrm{RH}$ and $\mathrm{FH}$ patients. ${ }^{2,9}$

Recently, impedance values for evaluating esophageal mucosal integrity (eg, MNBI) and chemical clearance (eg, PSPW index) have been proposed. ${ }^{14-17} \mathrm{MNBI}$ is calculated as the mean of 3 values obtained during 10-minute periods in the night, accurately reflecting the nocturnal period. ${ }^{14} \mathrm{PSPW}$ index reflects the integrity of the esophageal primary peristalsis stimulated by refluxes. ${ }^{8,18}$ Analysis of $\mathrm{MII} / \mathrm{pH}$ based on MNBI and PSPW index can increase the diagnostic role of $\mathrm{MII} / \mathrm{pH},{ }^{8}$ and $\mathrm{MNBI}$ and PSPW index were efficiently distinguishing PPI-refractory $\mathrm{EE}$ from $\mathrm{FH}, \mathrm{RH}$ from $\mathrm{FH}$, and lack of improvement of impaired PSPW index is a major determinant of PPI refractoriness. ${ }^{19,20}$

MNBI and PSPW index progressively decline during the progression from $\mathrm{FH}$ to $\mathrm{NERD}$ and $\mathrm{EE},,^{1,21-23}$ and they may increase the diagnostic role of $\mathrm{MII} / \mathrm{pH}$, especially for differentiating GERD from those with $\mathrm{FH}^{7-9}$ Therefore, we aim to explore the role of esophageal proximal MNBI, distal MNBI, and PSPW index for differentiating among Chinese patients with heartburn. Our data suggest distal MNBI and PSPW index could significantly distinguish FH from the different causes of GERD, with cut-off values of $1890.6 \Omega$, and $27.5 \%$, respectively. According to these cut-off values, $13 / 78$ (16.67\%) FH patients had distal MNBI values less than $1890.6 \Omega, 16 / 78$ (20.51\%) FH patients had PSPW index values less than $27.5 \%$, and $6 / 78(7.69 \%) \mathrm{FH}$ patients had both abnormal values of dital MNBI and PSPW index. So, they may actually be classified into GERD compared to the conventional $\mathrm{MII} / \mathrm{pH}$.

Our study has some limitations. First, all subjects were recruited from one center, which may have resulted in selection bias. Second, the small number of patients might have limited the statistical power of the study. Third, there is no data of healthy volunteers as control. In addition, being retrospective study, there might be a possibility of misclassification of endoscopy negative patients in case of endoscopy carried out without stopping PPI. However, to our knowledge, this study is the first to show that esophageal distal MNBI and PSPW index could increase the diagnostic role of $\mathrm{MII} / \mathrm{pH}$ in Chinese heartburn patients.

In the current study, distal MNBI and PSPW index values decreased significantly as the disease progressed from $\mathrm{FH}$ and RH to NERD and EE. In addition, distal MNBI and PSPW index values were significantly negatively correlated with acid reflux events, but not with nonacid reflux events. Therefore, acid reflux might be more damaging with respect to esophageal mucosal integ- 
rity and clearance function. In summary, esophageal distal MNBI and PSPW index could increase the diagnostic role of $\mathrm{MII} / \mathrm{pH}$, especially for differentiating Chinese patients with heartburn.

Acknowledgements: We thank all participants in this research.

Financial support: This work was supported by the Beijing Hospitals Authority Youth Programme (Code: QML20170606).

\section{Conflicts of interest: None.}

Author contributions: Ya Mei Sun was responsible for analyzing and interpreting the data, and drafting the manuscript; Yan Gao analyzed and interpreted the data; and Feng Gao was corresponding author, and was responsible for designing study, editing, and revising the draft.

\section{References}

1. Aziz Q, Fass R, Gyawali CP, Miwa H, Pandolfino JE, Zerbib F. Functional esophageal disorders. Gastroenterology 2016;150:1368-1379.

2. Hachem C, Shaheen NJ. Diagnosis and management of functional heartburn. Am J Gastroenterol 2016;111:53-61.

3. Surdea Blaga T, Dumitrascu D, Galmiche JP, Bruley des Varannes S. Functional heartburn: clinical characteristics and outcome. Eur J Gastroenterol Hepatol 2013;25:282-290.

4. Savarino E, Zentilin P, Tutuian R, et al. Impedance-pH reflux patterns can differentiate non-erosive reflux disease from functional heartburn patients. $\mathrm{J}$ Gastroenterol 2012;47:159-168.

5. Frazzoni M, Bertani H, Manta R, et al. Impairment of chemical clearance is relevant to the pathogenesis of refractory reflux oesophagitis. Dig Liver Dis 2014;46:596-602.

6. de Bortoli N, Martinucci I, Savarino E, et al. Association between baseline impedance values and response proton pump inhibitors in patients with heartburn. Clin Gastroenterol Hepatol 2015;13:1082-1088.e1.

7. Frazzoni M, Savarino E, de Bortoli N, et al. Analyses of the post-reflux swallow-induced peristaltic wave index and nocturnal baseline impedance parameters increase the diagnostic yield of impedance-pH monitoring of patients with reflux disease. Clin Gastroenterol Hepatol 2016;14:40-46.

8. Frazzoni M, de Bortoli N, Frazzoni L, et al. Impairment of chemical clearance and mucosal integrity distinguishes hypersensitive esophagus from functional heartburn. J Gastroenterol 2017;52:444-451.

9. Yamasaki T, Fass R. Reflux hypersensitivity: a new functional esophageal disorder. J Neurogastroenterol Motil 2017;23:495-503.

10. Gyawali CP, Kahrilas PJ, Savarino E, et al. Modern diagnosis of GERD: the Lyon consensus. Gut 2018;67:1351-1362.
11. Shay S, Tutuian R, Sifrim D, et al. Twenty-four hour ambulatory simultaneous impedance and $\mathrm{pH}$ monitoring: a multicenter report of normal values from 60 healthy volunteers. Am J Gastroenterol 2004;99:1037-1043.

12. Kushnir VM, Sathyamurthy A, Drapekin J, Gaddam S, Sayuk GS, Gyawali CP. Assessment of concordance of symptom reflux association tests in ambulatory pH monitoring. Aliment Pharmacol Ther 2012;35:10801087.

13. Patel A, Sayuk GS, Gyawali CP. Parameters on esophageal pH-impedance monitoring that predict outcomes of patients with gastroesophageal reflux disease. Clin Gastroenterol Hepatol 2015;13:884-891.

14. Martinucci I, de Bortoli N, Savarino E, et al. Esophageal baseline impedance levels in patients with pathophysiological characteristics of functional heartburn. Neurogastroenterol Motil 2014;26:546-555.

15. Patel A, Wang D, Sainani N, Sayuk GS, Gyawali CP. Distal mean nocturnal baseline impedance on $\mathrm{pH}$-impedance monitoring predicts reflux burden and symptomatic outcome in gastro-oesophageal reflux disease. Aliment Pharmacol Ther 2016;44:890-898.

16. Frazzoni M, Manta R, Mirante VG, Conigliaro R, Frazzoni L, Melott G. Esophageal chemical clearance is impaired in gastro-esophageal reflux disease--a 24-h impedance-pH monitoring assessment. Neurogastroenterol Motil 2013;25:399-406, e295.

17. Shafik A, El-Sibai O, Shafik AA, Mostafa R. Effect of topical esophageal acidification on salivary secretion: identification of the mechanism of action. J Gastroenterol Hepatol 2005;20:1935-1939.

18. Frazzoni L, Frazzoni M, de Bortoli N, et al. Postreflux swallow-induced peristaltic wave index and nocturnal baseline impedance can link PPIresponsive heartburn to reflux better than acid exposure time. Neurogastroenterol Motil 2017;29:e13116.

19. Frazzoni M, de Bortoli N, Frazzoni L, et al. The added diagnostic value of postreflux swallow-induced peristaltic wave index and nocturnal baseline impedance in refractory reflux disease studied with on-therapy impedancepH monitoring. Neurogastroenterol Motil 2017;29:e12947.

20. Frazzoni M, Frazzoni L, Tolone S, De Bortoli N, Savarino V, Savarino E. Lack of improvement of impaired chemical clearance characterizes PPIrefractory reflux-related heartburn. Am J Gastroenterol 2018;113:670-676.

21. Ribolsi M, Savarino E, de Bortoli N, et al. Reflux pattern and role of impedance-pH variables in predicting PPI response in patients with suspected GERD-related chronic cough. Aliment Pharmacol Ther 2014;40:966973.

22. van Rhijn BD, Weijenborg PW, Verheij J, et al. Proton pump inhibitors partially restore mucosal integrity in patients with proton pump inhibitorresponsive esophageal eosinophilia but not eosinophilic esophagitis. Clin Gastroenterol Hepatol 2014;12:1815-1823, e2.

23. Rinsma NF, Farré R, Bouvy ND, Masclee AA, Conchillo JM. The effect of endoscopic fundoplication and proton pump inhibitors on baseline impedance and heartburn severity in GERD patients. Neurogastroenterol Motil 2015;27:220-228. 